\title{
1 Thermal decomposition of barium trifluoroacetate thin films
}

2

3

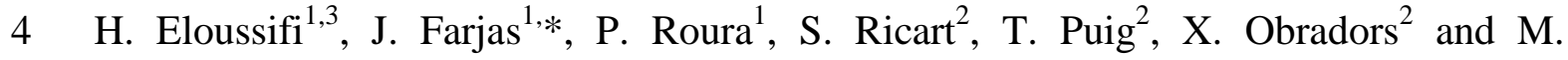

5 Dammak $^{3}$

6 University of Girona, Campus Montilivi, Edif. PII, E17071 Girona, Catalonia, Spain

$7 \quad{ }^{2}$ Institut de Ciència de Materials de Barcelona (CSIC), Campus de la UAB, 08193

8 Bellaterra, Catalonia, Spain

$9{ }^{3}$ Laboratoire de Chimie Inorganique, Faculté des Sciences de Sfax, Université de Sfax, 10 BP 1171, 3000 Sfax, Tunisia

\begin{abstract}
The thermal decomposition of barium trifluoroacetate thin films under different atmospheres is presented. Thermogravimetry and evolved gas analysis have been used for this in situ analysis. We focus our attention on the different behavior exhibited by films when compared to powders. The decomposition of barium trifluoroacetate is altered due to the faster out-diffusion of the product reaction : $\mathrm{CF}_{2}$. After barium trifluoroacetate decomposition a stable intermediate, barium fluoride, is formed. The decomposition of barium fluoride is diffusion controlled and depends on water partial pressure.
\end{abstract}

Keywords: barium trifluoroacetate, BaTFA, barium fluoride, thin films, thermal decomposition, TG, EGA, mass spectrometry.

*Corresponding author: jordi.farjas@udg.edu, Tel (34)972418490, Fax (34) 972418098 University of Girona, Campus Montilivi, Edif. PII, E17071 Girona, Catalonia, Spain 28 


\section{Introduction}

3 Chemical solution deposition (CSD) is an efficient, flexible, low cost and scalable

4 method for the fabrication of functional oxide films [1-3]. CSD involves solution

5 preparation, solution deposition, a low temperature thermal treatment to remove the

6 organic species and a high temperature thermal treatment to crystallize the amorphous

7 films. Thermal analysis (TA) is especially suited to analyzing the low temperature

8 treatment due to its ability to monitor in situ the processes that take place during

9 precursor decomposition as well as their dependence on the treatment conditions:

10 temperature program and oxygen and water partial pressures [4-9]. Knowledge of the

11 transport mechanism that affects the thermal decomposition of the organic precursor is

12 essential for CSD processing [10-12].

13 Although CSD is used to synthesize films, TA is routinely performed on 14 powders, TA analysis on films is very scarce. In general, the main reason for this is that 15 the signal measured by TA techniques is proportional to the sample mass. For instance, 16 typical sample masses for thermogravimetric measurements on powders are around 10 $17 \mathrm{mg}$ whereas film masses are, at best, one order of magnitude smaller. In addition, 18 precursor decomposition usually involves solid-gas reactions that strongly depend on 19 transport phenomena: in-diffusion of reactants, out-diffusion of products or heat 20 dissipation in exothermic processes. As a result, the behavior of powders may strongly 21 differ from the actual behavior of films [13-16].

In this paper we will analyze the thermal decomposition of barium 23 trifluoroacetate, $\mathrm{Ba}\left(\mathrm{CF}_{3} \mathrm{COO}\right)_{2}\left(\mathrm{Ba}(\mathrm{TFA})_{2}\right)$, in the form of films. $\mathrm{Ba}(\mathrm{TFA})_{2}$, combined with yttrium and copper precursors, is the most common precursor in the fabrication of high-performance $\mathrm{YBa}_{2} \mathrm{Cu}_{3} \mathrm{O}_{7-\delta} \quad(\mathrm{YBCO})$ superconducting films $[12,17,18]$. Thermogravimetry (TG) is used to monitor the decomposition process. A mass spectrometer (MS) is used to perform the evolved gas analysis (EGA) of volatiles formed during decomposition. Intermediate and final products are characterized using scanning electron microscopy (SEM), energy dispersive X-ray micro-analysis (EDX) and X-ray diffraction (XRD). Different atmospheres have been tested. We will show that $\mathrm{Ba}(\mathrm{TFA})_{2}$ films decompose differently to powders [19-21] and that $\mathrm{BaF}_{2}$ decomposition kinetics is controlled by HF diffusion.

\section{Experimental}


2 The synthesis of barium trifluoroacetate $\mathrm{Ba}\left(\mathrm{CF}_{3} \mathrm{COO}\right)_{2}$ powders is described in ref.

3 [21]. A solution $0.56 \mathrm{M}$ of $\mathrm{Ba}(\mathrm{TFA})_{2}$ in anhydrous methyl alcohol was obtained at room

4 temperature by manually shaking the mixture for less than 1 minute. Films were

5 prepared by manually freely spreading microdrops $(\sim 2 \mu \mathrm{L})$ on the surface of a glass disc

6 (12 $\mathrm{mm}$ in diameter) or on a square LAO plate $\left(10 \times 10 \mathrm{~mm}^{2}\right)$. The solvent was removed

7 by heating the substrate at $70^{\circ} \mathrm{C}$ for 15 minutes in a hot plate under vacuum. After

8 solvent evaporation, the masses of the films vary from 0.21 to $2.0 \mathrm{mg}$.

9 TG analysis was performed with a Setaram apparatus model, Setsys Evolution

10 16. To improve the signal-noise ratio, two substrates coated on both sides were analyzed

11 simultaneously. Gas flow was controlled by mass flow meters. High-purity nitrogen,

12 argon, oxygen and synthetic air were used. Water-saturated gases were obtained by

13 bubbling the carrier gas in water at standard temperature and pressure $\left(25^{\circ} \mathrm{C}, 1 \mathrm{~atm}\right)$. TG

14 curves were corrected by subtracting a consecutive identical second measurement that

15 was performed without opening the furnace to ensure that the differences between the

16 first and second measurements were minimal. In addition, the mass of the final residue

17 was measured at room temperature with an analytical balance that allows us to

18 determine the absolute mass with accuracy better than $5 \mu \mathrm{g}$. Then, the TG curve is

19 vertically shifted so that the final mass of the TG curve coincides with that measured at

20 room temperature. Residual oxygen and water partial pressures on the furnace were

$210.01 \%$ and $0.002 \%$, respectively. Simultaneous TG and EGA analyses were performed

22 with a Mettler Toledo, model TGA851eLF, thermobalance coupled to an MKS

23 quadrupole mass spectrometer (Microvision Plus). Residual oxygen and water partial

24 pressures on the TGA851eLF furnace were $0.2 \%$ and $0.04 \%$, respectively.

25 Complementary EGA analyses were performed by placing the samples inside a quartz

26 tube at a pressure of around $10^{-6}$ mbar. Samples were heated using an external furnace.

27 Thermal analysis experiments were performed at heating rates of 5,10 and $20 \mathrm{~K} / \mathrm{min}$.

28 XRD experiments were done in a SMART APEX diffractometer from Bruker

29 AXS. The X-ray beam wavelength was $0.710730 \AA$ (Mo-K $\alpha)$. The X-ray source was

30 operated at a voltage of $50 \mathrm{kV}$ and a current of $3 \mathrm{~mA}$. SEM and EDX observations were

31 performed in a Zeiss DSM 960A scanning electron microscope operated at $20 \mathrm{kV}$.

32 Samples were coated with a thin gold or carbon films to remove electrostatic charges.

34 3. Results 
In Figs. 1 and 2 we have plotted the mass variation when $\mathrm{Ba}(\mathrm{TFA})_{2}$ films are heated at $20 \mathrm{~K} / \mathrm{min}$ in dry and wet atmospheres with different oxygen content. The mass loss evolution can be divided into three stages. The first stage (below $150^{\circ} \mathrm{C}$ ) corresponds to dehydration. The larger mass loss takes place at the second stage, which starts at $220^{\circ} \mathrm{C}$ and is related to precursor decomposition. The mass of the solid residue after precursor decomposition remains constant in a wide temperature range and corresponds to the expected mass of $\mathrm{BaF}_{2}$ :

$$
\mathrm{m}\left[\mathrm{BaF}_{2}\right] / \mathrm{m}\left[\mathrm{Ba}\left(\mathrm{CF}_{3} \mathrm{COO}\right)_{2}\right] \cdot 100=48.25 \% .
$$

The formation of $\mathrm{BaF}_{2}$ has been confirmed by XRD analysis. Fig 3 shows that the product, when films are heated up to $400^{\circ} \mathrm{C}$ at $20 \mathrm{~K} / \mathrm{min}$ in dry and wet argon and air atmospheres, is mainly crystalline $\mathrm{BaF}_{2}$. The formation of $\mathrm{BaF}_{2}$ instead of $\mathrm{BaO}$ or $\mathrm{BaCO}_{3}$ is due to the high electronegativity of fluorine which displaces the oxygen 14 bonded to $\mathrm{Ba}[18]$.

SEM analysis of the films obtained under different atmospheres has revealed that the thickness is quite inhomogeneous (see Fig. 4.a). This result is not surprising if we take into account that the solution deposition method (drop coating) results in inhomogeneous films due to the enhanced solvent evaporation at the rim of the deposited layer: the so-called "coffee ring effect" [22-24]. The thickness may vary a factor of two from the central region to the rim of the film. In addition, the actual film density is significantly smaller than the bulk density of $\mathrm{BaF}_{2}$. For instance, from Fig. 4.a, one can determine the film thickness which is around $1.6 \mu \mathrm{m}$ whereas from the mass of this film we have obtained a rough estimation of the film density, $2.6 \mathrm{~g} / \mathrm{cm}^{3}$ which is significantly smaller than that of bulk $\mathrm{BaF}_{2}\left(\rho\left(\mathrm{BaF}_{2}\right)=4.89 \mathrm{~g} / \mathrm{cm}^{3}\right)$. As to the microstructure, we have not observed any significant differences between the films obtained under different atmospheres (see Figs. $4 b$ and 4.c).

Contrarily to the results reported in the literature for powders [20,21], the decomposition of films does not exhibit any dependence on the oxygen or water partial pressure. This can be clearly observed in the insets of Figs. 1 and 2, where curves obtained under different oxygen and water partial pressures overlap. Especially remarkable, is the nearly perfect overlapping in the case of dry atmospheres.

In Fig 5 we have plotted the main volatiles formed during $\mathrm{Ba}(\mathrm{TFA})_{2}$ 33 decomposition. EGA has been carried out in vacuum $\left(10^{-6} \mathrm{mbar}\right)$. EGA reveals two 34 different steps. In that of below $325^{\circ} \mathrm{C}$, similar amounts of $\mathrm{CO}_{2}$ and $\mathrm{CO}$ are formed 
$1 \quad\left(\left[\mathrm{CO}_{2}\right]^{+}(\mathrm{m} / \mathrm{z}=44)\right.$ and $\left.[\mathrm{CO}]^{+}(\mathrm{m} / \mathrm{z}=28)\right)$. In this first step the more abundant volatile 2 containing fluorine is $\mathrm{CF}_{3} \mathrm{CFO}$ (In ref. [21], ions $\left[\mathrm{CF}_{3}\right]^{+}(\mathrm{m} / \mathrm{z}=69)$ and $[\mathrm{COF}]^{+}(\mathrm{m} / \mathrm{z}=47)$ were assigned to the formation of $\mathrm{CF}_{3} \mathrm{CFO}$ ) whereas when above $325^{\circ} \mathrm{C}$ the larger amount of volatiles is formed. This second step is characterized by a significantly larger quantity of $\mathrm{CO}_{2}$ (approximately twice the amount of $\mathrm{CO}$ ) and the more abundant volatile containing fluorine is the difluorocarbene molecule, $: \mathrm{CF}_{2}$ (ions $[\mathrm{CF}]^{+}(\mathrm{m} / \mathrm{z}=31)$ and $\left.\left[\mathrm{CF}_{2}\right]^{+}(\mathrm{m} / \mathrm{z}=50)\right)$.

This tendency is also observed in measurements carried out at atmospheric pressure. In Fig 6 we have plotted the result of the simultaneous TG-EGA analysis of a very thick film. The EGA sensibility for films is significantly reduced, with respect to powders, because of the smaller mass and the larger surface that results in a higher gas dilution. Thus, to perform the simultaneous TG-EGA, we are forced to work with very thick films. When compared to powders [21], in Fig. 6 we observe larger quantities of $: \mathrm{CF}_{2}$ and the amount of $\mathrm{CO}_{2}$ is significantly larger than that of $\mathrm{CO}$. However, compared to the EGA analysis in vacuum the differences, with respect to powders, are less pronounced.

According to the mechanisms proposed for powders in ref. [21], the decomposition of $\mathrm{Ba}(\mathrm{TFA})_{2}$ is initiated by the two consecutive reactions:

$$
\begin{aligned}
& \left(\mathrm{CF}_{3} \mathrm{COO}\right)_{2} \mathrm{Ba} \leftrightarrow \mathrm{CF}_{3} \mathrm{COOBaF}+: \mathrm{CF}_{2}+\mathrm{CO}_{2} \\
& \mathrm{CF}_{3} \mathrm{COOBaF}+: \mathrm{CF}_{2} \leftrightarrow \mathrm{BaF}_{2}+\mathrm{CF}_{3} \mathrm{CFO}+\mathrm{CO}
\end{aligned}
$$

Note that reactions (2) and (3) involve the formation of equal amounts of $\mathrm{CO}$ and $\mathrm{CO}_{2}$, and the formation of $\mathrm{CF}_{3} \mathrm{CFO}$ as the main volatile containing fluorine, is in agreement with the EGA results for the first decomposition step. However, the second step involves a larger formation of $\mathrm{CO}_{2}$ and $: \mathrm{CF}_{2}$. This scenario is compatible with the reaction [20]:

$$
\mathrm{CF}_{3} \mathrm{COOBaF} \leftrightarrow \mathrm{BaF}_{2}+: \mathrm{CF}_{2}+\mathrm{CO}_{2}
$$

Thus, two different mechanisms compete for the decomposition of $\mathrm{CF}_{3} \mathrm{COOBaF}$, reactions (3) and (4). While the decomposition is initiated by reaction (3), during the decomposition reactions (3) and (4) coexist. In the case of thin films in vacuum, reaction (4) is clearly enhanced, being the main decomposition path above $325^{\circ} \mathrm{C}$ (see Fig. 5).

The last stage at high temperature $\left(\sim 1200^{\circ} \mathrm{C}\right)$ corresponds to the decomposition of $\mathrm{BaF}_{2}$. EDX shows that the final solid residue contains barium and oxygen but the final mass of the solid residue is below the expected mass for metallic $\mathrm{Ba}$, thus some $\mathrm{Ba}$ 
1 is volatilized at the last decomposition stage. TA measurements in powders $[20,21]$

2 have stated that $\mathrm{BaF}_{2}$ is stable up to $1200^{\circ} \mathrm{C}$ (in dry or wet atmospheres). From Fig. 1, 3 one can observe that, in films and in wet atmosphere, $\mathrm{BaF}_{2}$ decomposition temperature 4 is shifted down to around $100^{\circ} \mathrm{C}$. Also, in Fig. 7, one can observe that, for a given 5 thickness, films decompose at a lower temperature in the presence of water. Thus, the 6 analysis on films shows that $\mathrm{BaF}_{2}$ decomposition is controlled by diffusion, and that 7 water plays a key role in its decomposition.

Transformations controlled by gas diffusion exhibit a dependence on the film thickness [25]. In Fig 7 one can observe that the thicker the films (larger mass) are, the higher the $\mathrm{BaF}_{2}$ decomposition temperature is. Since the distance of diffusion is significantly longer in powders, their decomposition temperature is shifted to higher temperatures (see Fig. 1). Therefore, in the case of solid-gas reactions, films may decompose at significantly lower temperatures than powders. This means that decomposition temperatures drawn from TA experiments on powders may significantly differ from their actual values in films $[13,14,16]$.

Conversely, in Fig. 7 we do not observe any dependence of the decomposition temperature of $\mathrm{Ba}(\mathrm{TFA})_{2}$ on the film thickness $\left(\sim 350^{\circ} \mathrm{C}\right)$. This result would indicate that, in the thickness range examined, kinetics is not controlled by diffusion of reactive or product gases. This result is in agreement with the observed independence of the reaction kinetics on the oxygen and water partial pressures, previously reported. Again, this result is in contrast with the observed behavior in powders [21].

\section{Discussion}

Contrarily to powders, the decomposition of $\mathrm{Ba}(\mathrm{TFA})_{2}$ in films does not exhibit any dependence on the oxygen partial pressure. In powders [21], the dependence on the oxygen partial pressure was explained in terms of reaction (3); reaction (3) results in the formation of $\mathrm{CO}$, thus an accumulation of $\mathrm{CO}$ in the voids between particles may reduce the decomposition kinetics. The presence of $\mathrm{O}_{2}$ provides an efficient path to decrease the local partial pressure of $\mathrm{CO}$, thus it enhances the decomposition rate. In the case of films, the large surface to volume ratio significantly facilitates the $\mathrm{CO}$ removal and accordingly, the presence of oxygen to boost the reaction is no longer necessary. Therefore, no influence on the oxygen partial pressure is observed.

In the case of powders [21] two different mechanisms were proposed to explain

34 the dependence on the $\mathrm{p}\left(\mathrm{O}_{2}\right)$ : the removal of $\mathrm{CO}$ and the local overheating related to $\mathrm{CO}$ 
1 combustion. If the main reason for the lower temperature decomposition in the presence

2 of $\mathrm{O}_{2}$ were the local overheating, one would expect a higher temperature decomposition 3 in films due the absence of local overheating in films $[15,16]$. Note that, due to the local

4 overheating in powders, the decomposition temperature increases when the sample mass 5 is reduced (see Fig. 6 in ref. [21]). However, Fig. 1 shows that films decompose at 6 lower temperatures than powders. This lower temperature decomposition in films is due 7 to the enhanced gas transport. One should be very careful when extrapolating from the 8 behavior observed in powders for small sample masses, to films.

In both films and powders, reactions (3) and (4) are two competing mechanisms for the decomposition of $\mathrm{CF}_{3} \mathrm{COOBaF}$. Difluorocarbene, $\mathrm{CF}_{2}$, is a reactive in reaction 11 (3) while it is a product in reaction (4). Thus, a high concentration of : $\mathrm{CF}_{2}$ would 12 promote reaction (3) against reaction (4), while a low concentration of : $\mathrm{CF}_{2}$ would do 13 just the opposite. In the case of powders, the trapped $: \mathrm{CF}_{2}$ makes reaction (3) the 14 dominant path. On the contrary, in films outdiffusion of $: \mathrm{CF}_{2}$ is much faster, hence reaction (4) is the main decomposition path (in the case of vacuum, the removal of : $\mathrm{CF}_{2}$ is further promoted). Essentially, the lack of dependence of the $\mathrm{Ba}(\mathrm{TFA})_{2}$ decomposition kinetics in the film thickness confirms that : $\mathrm{CF}_{2}$ is efficiently removed.

It is important to note in the case of powders that, the formation of local atmospheres in the interstices between particles may alter the reaction kinetics, promoting secondary reactions of reaction products and may result in a spatially inhomogeneous reaction [15]. Conversely, in-transport of reactive gas and out-transport of reaction volatiles in films is clearly enhanced. Therefore, in general, TA in films allows a better understanding of the intrinsic kinetics of solid-gas reactions.

It is generally assumed that fluorides decomposition is governed by the reaction:

$$
\mathrm{BaF}_{2}+\mathrm{H}_{2} \mathrm{O} \leftrightarrow \mathrm{BaO}+2 \mathrm{HF},
$$

and that the kinetics is controlled by the out-diffusion of HF. Therefore, due to the enhanced diffusion in films, with respect to powders, decomposition in films takes place at significantly lower temperature (around $100^{\circ} \mathrm{C}$ lower). We have also observed that the kinetics depend on the $\mathrm{p}\left(\mathrm{H}_{2} \mathrm{O}\right)$ being significantly enhanced in the presence of water, 30 in agreement with reaction (5). However, despite the fact that $\mathrm{BaF}_{2}$ decomposition is significantly enhanced in films, its decomposition temperature is still too high to understand the YBCO formation. Metal TFAs are used in the synthesis of YBCO to prevent the formation of the highly stable $\mathrm{BaCO}_{3}[12,18,26,27]$. However, the high stability of $\mathrm{BaF}_{2}$ is in contrast to the formation of $\mathrm{YBCO}$ below $800^{\circ} \mathrm{C}$. It has been 
1 proposed [12] that after precursor decomposition, a barium yttrium fluoride is formed

2 that will decompose at a much lower temperature than $\mathrm{BaF}_{2}$, thus allowing the 3 formation of YBCO. Nonetheless, our TA measurements in films show that film 4 thickness, water partial pressure and gas flow are key parameters in controlling the 5 fluoride decomposition and eventually the quality of YBCO films, as stated by several 6 authors $[10,12,18]$. It is also noteworthy that $\mathrm{BaF}_{2}$ decomposition takes place in dry 7 atmosphere as well, albeit at a higher temperature (Fig. 7). The reason being, that 8 reaching inert conditions in films is much more difficult to achieve due to their high 9 surface to volume ratio. In our case, the residual water partial pressure $10\left(\mathrm{p}\left(\mathrm{H}_{2} \mathrm{O}\right)<0.002 \%\right)$ is sufficient to decompose $\mathrm{BaF}_{2}$ but at a significantly lower rate when compared to wet conditions. It is worth noting that we have not observed $\mathrm{BaF}_{2}$ decomposition in powders and dry atmosphere.

\section{Conclusions}

Thermal decomposition of barium trifluoroacetate films under different atmospheres has been analyzed. Differences between the behavior in films and powder have been highlighted and analyzed. Due to the shorter diffusion path and to the higher surface to volume ratio, heat and gas renewal and transport is clearly enhanced in films. As a result, the observed behavior in films strongly differs from that of powders. We have observed different decomposition temperatures, different atmosphere dependences and the main decomposition mechanism is also modified.

In particular, $\mathrm{Ba}(\mathrm{TFA})_{2}$ decomposition does not depend on the oxygen and water partial pressure. The decomposition is initiated by a mechanism that entails the formation of $\mathrm{CO}, \mathrm{CO}_{2}$ and $\mathrm{CF}_{3} \mathrm{CFO}$, however, the main decomposition path involves the formation of $\mathrm{CO}_{2}$ and $: \mathrm{CF}_{2}$.

The solid residue after $\mathrm{Ba}(\mathrm{TFA})_{2}$ is face-centered cubic $\mathrm{BaF}_{2}$. In the presence of water, $\mathrm{BaF}_{2}$ decomposes at around $1200^{\circ} \mathrm{C}$. The decomposition of $\mathrm{BaF}_{2}$ is controlled by HF out-diffusion and thus gas flow, film thickness and water partial pressure are key parameters to control the decomposition of $\mathrm{BaF}_{2}$.

Our results indicate that the actual behavior on films may strongly differ from that of powders, i.e., in general, the conclusion drawn from the TA of metal organic precursors in the form of powders cannot be extrapolated to film synthesis through chemical solution deposition. Besides, TA in films opens up new perspectives to the contribution of TA in the synthesis of advanced oxides films through chemical methods. 
2 of the intrinsic kinetics of the reactions that take place.

3

4 Acknowledgements

5 This work was partially funded by the Spanish Programa Nacional de 6 Materiales through projects MAT2011-28874-C02-01 and MAT2011-28874-C02-02, 7 by the Consolider program Nanoselect, CSD2007-00041, EU project NESPA-RTN and 8 by the Generalitat de Catalunya contracts No. 2009SGR-185 and 2009SGR-770. H. 9 Eloussifi acknowledges the financial support of the Tunisian Ministry of Higher 10 Education and Scientific Research. 


\section{Reference}

3 [1] R.W. Schwartz, T. Schneller, R. Waser, Chemical solution deposition of electronic 4 oxide films, C. R. Chim. 7 (2004) 433-461.

5 [2] V.C. Tung, M.J. Allen, Y. Yang, R.B. Kaner, High-throughput solution processing 6 of large-scale graphene, Nat. Nano. 4 (2009) 25-29.

7 [3] A. Llordés, K. Zalamova, S. Ricart, A. Palau, A. Pomar, T. Puig, A. Hardy, M.K.

8 Van Bael, X. Obradors, Evolution of Metal-Trifluoroacetate Precursors in the Thermal

9 Decomposition toward High-Performance $\mathrm{YBa}_{2} \mathrm{Cu}_{3} \mathrm{O}_{7}$ Superconducting Films, 10 Chem. Mater. 22 (2010) 1686-1694.

11 [4] J. Farjas, J. Camps, P. Roura, S. Ricart, T. Puig, X. Obradors, Thermoanalytical 12 study of the formation mechanism of yttria from yttrium acetate, Thermochim. Acta. $13521(2011) 84-89$.

14 [5] M. Mosiadz, K. Juda, S. Hopkins, J. Soloducho, B. Glowacki, An in-depth in situ IR 15 study of the thermal decomposition of yttrium trifluoroacetate hydrate, 16 J. Therm. Anal. Calorim. 107 (2012) 681-691.

17 [6] M. Mosiadz, K.L. Juda, S.C. Hopkins, J. Soloducho, B.A. Glowacki, An in-depth in 18 situ IR study of the thermal decomposition of copper trifluoroacetate hydrate, J. 19 Fluorine Chem. 135 (2012) 59-67.

20 [7] H. Eloussifi, J. Farjas, P. Roura, J. Camps, M. Dammak, S. Ricart, T. Puig, X. 21 Obradors, Evolution of Yttrium Trifluoroacetate Thermal Decomposition, 22 J. Therm. Anal. Calorim. 108 (2012) 589-596.

23 [8] P. Roura, J. Farjas, J. Camps, S. Ricart, J. Arbiol, T. Puig, X. Obradors, 24 Decomposition processes and structural transformations of cerium propionate into nanocrystalline ceria at different oxygen partial pressures, J. Nanopart. Res. 13 (2011) $26 \quad 4085-4096$.

27 [9] R. Szczęsny, E. Szłyk, Thermal decomposition of some silver(I) carboxylates under 28 nitrogen atmosphere, J Therm Anal Calorim. (DOI 10.1007/s10973-012-2485-1) 6.

29 [10] M. Yoshizumi, I. Seleznev, M.J. Cima, Reactions of oxyfluoride precursors for the 30 preparation of barium yttrium cuprate films, Physica C: Superconductivity. 403 (2004) 31 191-199.

32 [11] T. Puig, J.C. Gonzalez, A. Pomar, N. Mestres, O. Castano, M. Coll, J. Gazquez, F. 33 Sandiumenge, S. Pinol, X. Obradors, The influence of growth conditions on the 
1 microstructure and critical currents of TFA-MOD $\mathrm{YBa}_{2} \mathrm{Cu}_{3} \mathrm{O}_{7}$ films, Supercond. Sci.

2 Technol. 18 (2005) 1141-1150.

3 [12] X. Obradors, T. Puig, S. Ricart, M. Coll, J. Gazquez, A. Palau, X. Granados,

4 Growth, nanostructure and vortex pinning in superconducting $\mathrm{YBa}_{2} \mathrm{Cu}_{3} \mathrm{O}_{7}$ thin films

5 based on trifluoroacetate solutions, Supercond. Sci. Technol. 25 (2012) 123001.

6 [13] P. Vermeir, I. Cardinael, J. Schaubroeck, K. Verbeken, M. Bäcker, P. Lommens,

7 W. Knaepen, J. D'Haen, K. De Buysser, I. Van Driessche, Elucidation of the

8 Mechanism in Fluorine-Free Prepared $\mathrm{YBa}_{2} \mathrm{Cu}_{3} \mathrm{O}_{7-\delta}$ Coatings, Inorg. Chem. 49 (2010) $9 \quad 4471-4477$.

10 [14] P. Roura, J. Farjas, S. Ricart, M. Aklalouch, R. Guzman, J. Arbiol, T. Puig, A.

11 Calleja, O. Peña-Rodríguez, M. Garriga, X. Obradors, Synthesis of nanocrystalline ceria

12 thin films by low-temperature thermal decomposition of Ce-propionate, Thin Solid 13 Films. 520 (2012) 1949-1953.

14 [15] J. Farjas, D. Sanchez-Rodríguez, H. Eloussifi, R.C. Hidalgo, P. Roura, S. Ricart, T. 15 Puig, X. Obradors, Can We Trust on the Thermal Analysis of Metal Organic Powders 16 for thin film preparation? in: M. Jain, X. Obradors, Q. Jia, R.W. Schwartz (Eds.), 17 Solution Synthesis of Inorganic Films and Nanostructured Materials, Cambridge 18 Journals Online, 2012, pp. 13-17.

19 [16] D. Sanchez-Rodríguez, J. Farjas, P. Roura, S. Ricart, N. Mestres, T. Puig, X. 20 Obradors, Thermal analysis for low temperature synthesis of oxide thin films from 21 chemical solutions, J. Chem. Mat. C. (Submitted).

22 [17] M. Kullberg, M. Lanagan, W. Wu, R. Poeppel, A sol-gel method for preparing oriented $\mathrm{YBa}_{2} \mathrm{Cu}_{3} \mathrm{O}_{7-\delta}$ films on silver substrates, Supercond. Sci. Technol. 4 (1991) 337.

[18] T. Araki, I. Hirabayashi, Review of a chemical approach to $\mathrm{YBa}_{2} \mathrm{Cu}_{3} \mathrm{O}_{7-\mathrm{x}}$-coated superconductors-metalorganic deposition using trifluoroacetates,

27 Supercond. Sci. Technol. 16 (2003) R71-R94.

[19] R. Christian, A pyrolytic route to fluoride glasses. I. Preparation and thermal decomposition of metal trifluoroacetates, J. Non Cryst. Solids. 152 (1993) 161-166. [20] M. Mosiadz, K.L. Juda, S.C. Hopkins, J. Soloducho, B.A. Glowacki, An in-depth in situ IR study of the thermal decomposition of barium trifluoroacetate hydrate,

33 [21] J. Farjas, J. Camps, P. Roura, S. Ricart, T. Puig, X. Obradors, The thermal decomposition of barium trifluoroacetate, Thermochimica Acta. 544 (2012) 77-83. 
1 [22] N.D. Denkov, O.D. Velev, P.A. Kralchevsky, I.B. Ivanov, H. Yoshimura, K.

2 Nagayama, Two-dimensional crystallization, Nature. 361 (1993) 26-26.

3 [23] R.D. Deegan, O. Bakajin, T.F. Dupont, G. Huber, S.R. Nagel, T.A. Witten,

4 Capillary flow as the cause of ring stains from dried liquid drops, Nature. 389 (1997)

$5 \quad 827-829$.

6 [24] H. Hu, R.G. Larson, Evaporation of a Sessile Droplet on a Substrate, J Phys Chem

7 B. $106(2002)$ 1334-1344.

8 [25] F. Kail, J. Farjas, P. Roura, i.C. Roca, Molecular hydrogen diffusion in

9 nanostructured amorphous silicon thin films, Phys. Rev. B. 80 (2009) 073202.

10 [26] A. Gupta, R. Jagannathan, E.I. Cooper, E.A. Giess, J.I. Landman, B.W. Hussey,

11 Superconducting oxide films with high transition temperature prepared from metal

12 trifluoroacetate precursors, Appl. Phys. Lett. 52 (1988) 2077-2079.

13 [27] P.C. McIntyre, M.J. Cima, M.F. Ng, Metalorganic deposition of high-Jc

$14 \mathrm{Ba}_{2} \mathrm{YCu}_{3} \mathrm{O}_{7-x}$ thin films from trifluoroacetate precursors onto (100) SrTiO3, J. Appl.

15 Phys. 68 (1990) 4183-4187.

16 [28] JCPDS card no. 04-0452, The International Centre for Diffraction Data, Newton 17 Square, PA, USA. 


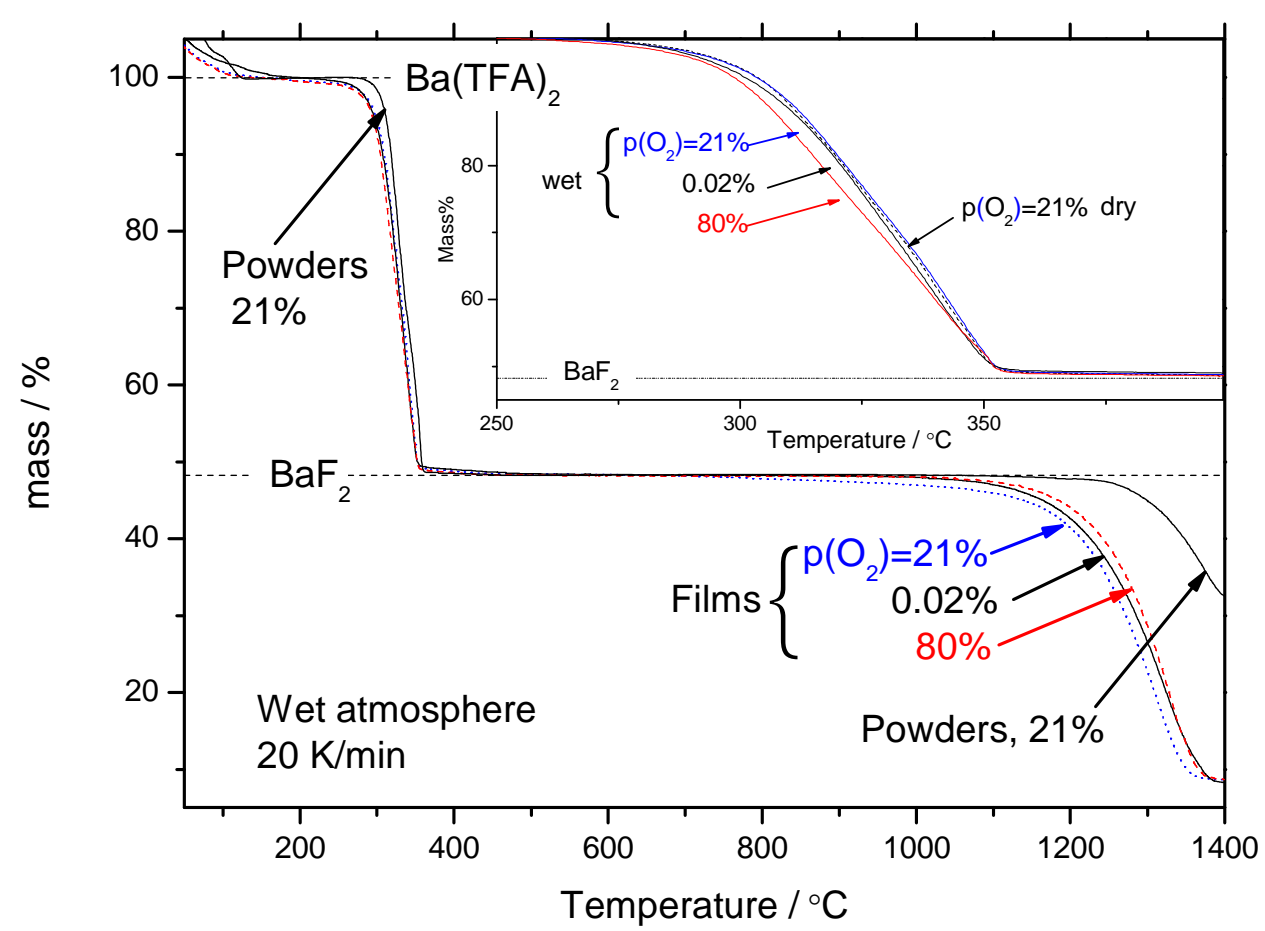

1

3 Figure 1. TG curves for thermal decomposition of Ba(TFA) $)_{2}$ films heated at $20 \mathrm{~K} / \mathrm{min}$

4 in wet atmospheres with different oxygen partial pressures: air (21\%), nitrogen and

5 oxygen mixture $\left(80 \% \mathrm{O}_{2}\right)$ and argon $(0.02 \%)$ and powders in wet air. Precursor masses

6 per unit surface of a single film, $m_{S}$, are $1.14,1.15$ and $1.19 \mathrm{mg} / \mathrm{cm}^{2}$ respectively. The

7 initial sample mass of powders was $18 \mathrm{mg}$. The mass has been normalized to the mass

8 after dehydration. Inset: detail of the precursor film decomposition for wet and dry

9 atmospheres and for different oxygen partial pressures. 


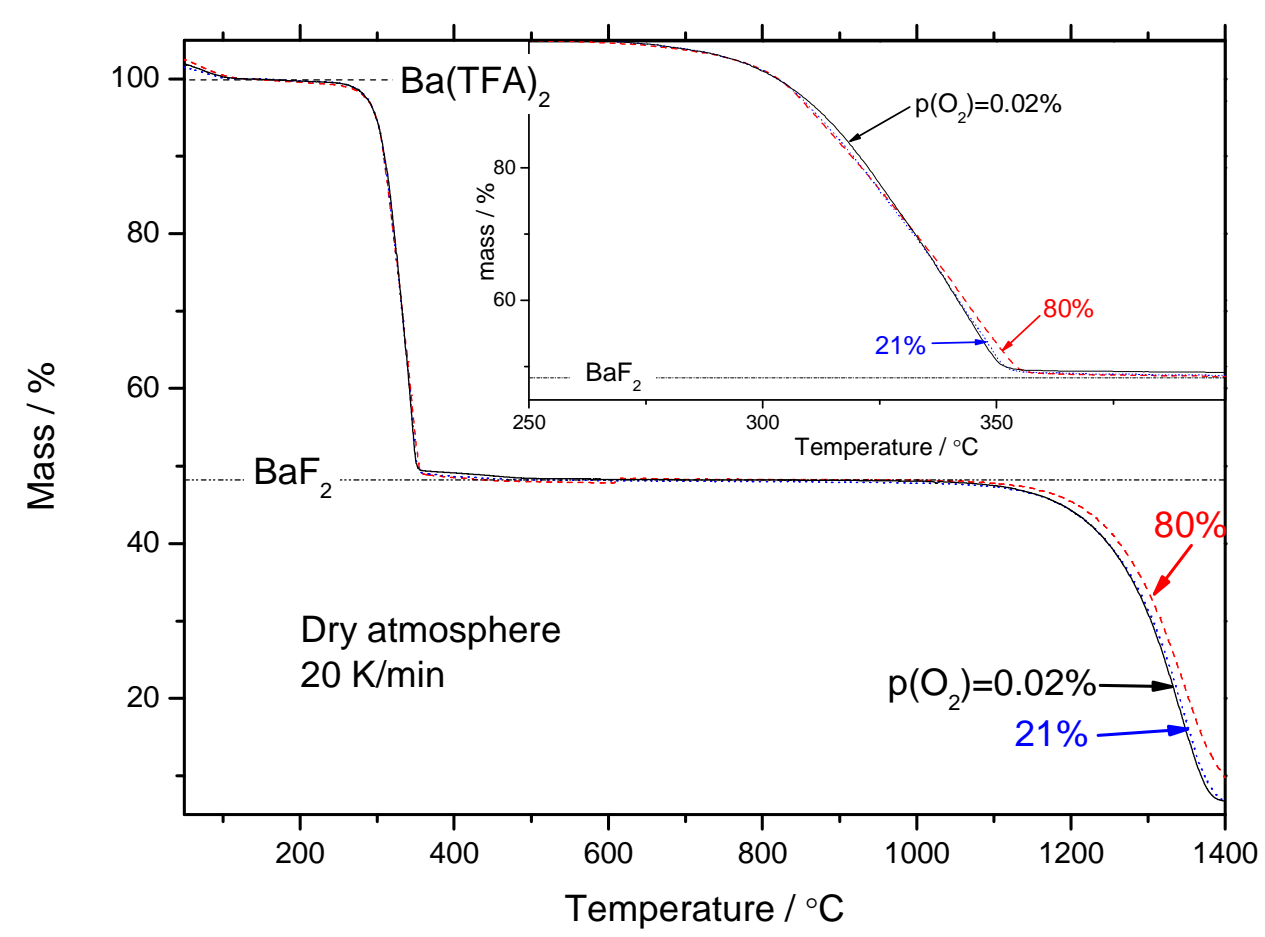

1

3 Figure 2. TG curves for thermal decomposition of $\mathrm{Ba}(\mathrm{TFA})_{2}$ heated at $20 \mathrm{~K} / \mathrm{min}$ in dry 4 atmospheres with different oxygen partial pressures: air (21\%, dotted line), nitrogen and 5 oxygen mixture $\left(80 \% \mathrm{O}_{2}\right.$, dashed line) and argon $\left(0.02 \%\right.$, solid line). Values of $m_{S}$ are $60.98,1.44$ and $1.29 \mathrm{mg} / \mathrm{cm}^{2}$ respectively. The mass has been normalized to the mass 7 after dehydration. Horizontal dotted line is the expected final mass for the formation of $8 \quad \mathrm{BaF}_{2}$. Inset: detail of the precursor decomposition. 


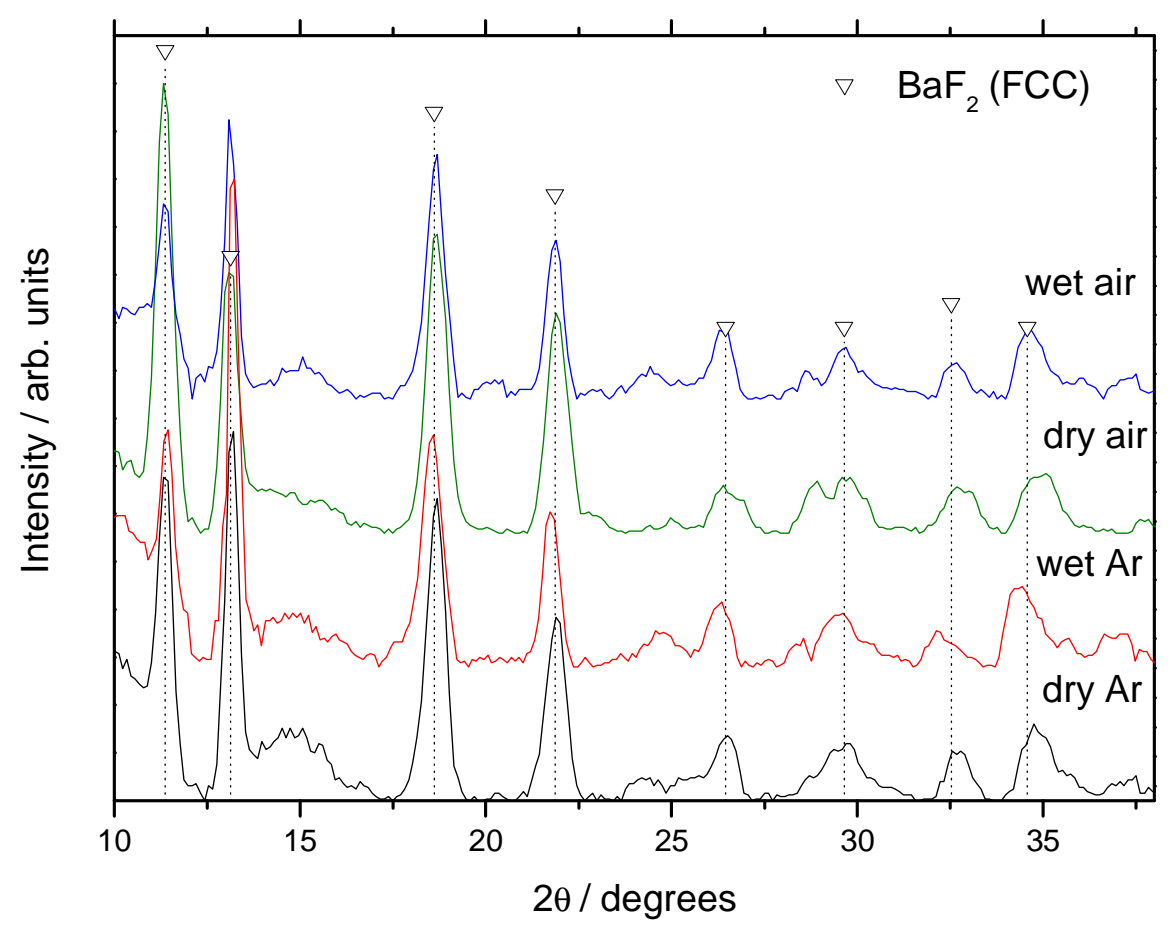

1

3 Figure 3. X-ray powder diffractograms of solid residues after heating the $\mathrm{Ba}(\mathrm{TFA})_{2}$ to $4400^{\circ} \mathrm{C}$ at $20 \mathrm{~K} / \mathrm{min}$ in different atmospheres. Triangles: face-centered $\mathrm{BaF}_{2}$ phase [28]. 5 

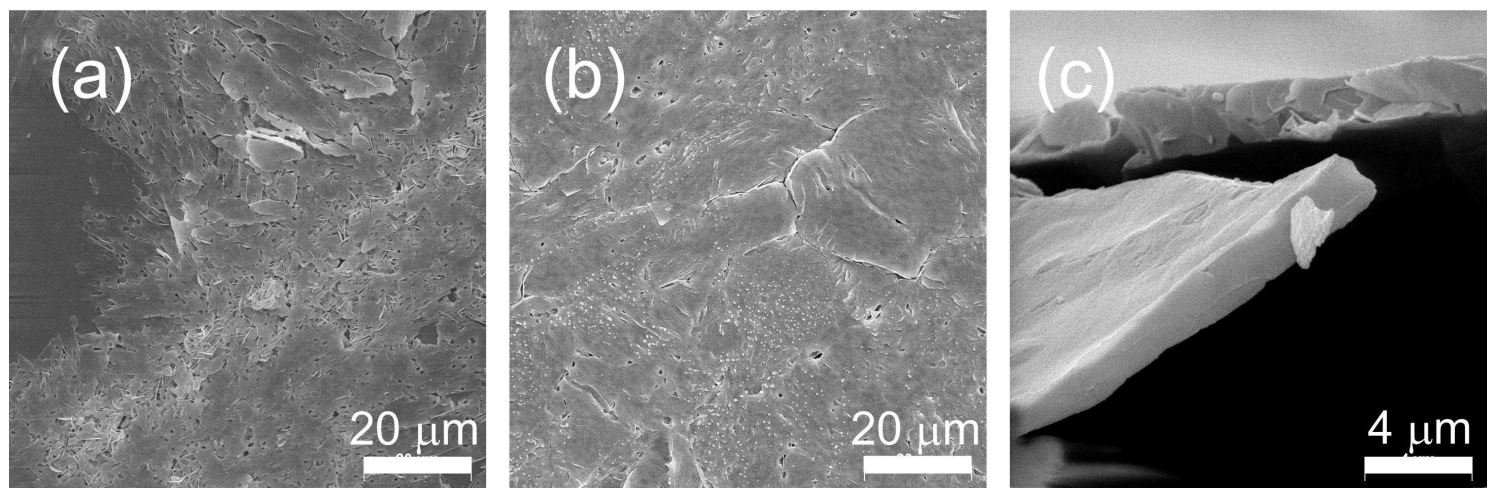

2 Figure 4. Scanning electron micrograph obtained when a $\mathrm{Ba}(\mathrm{TFA})_{2}$ film, $m_{s}=0.98$ $3 \mathrm{mg} / \mathrm{cm}^{2}$, is heated to $400^{\circ} \mathrm{C}$ at a constant rate of $20 \mathrm{~K} / \mathrm{min}$ in wet argon (a), synthetic air 4 (b) and dry argon (c). 


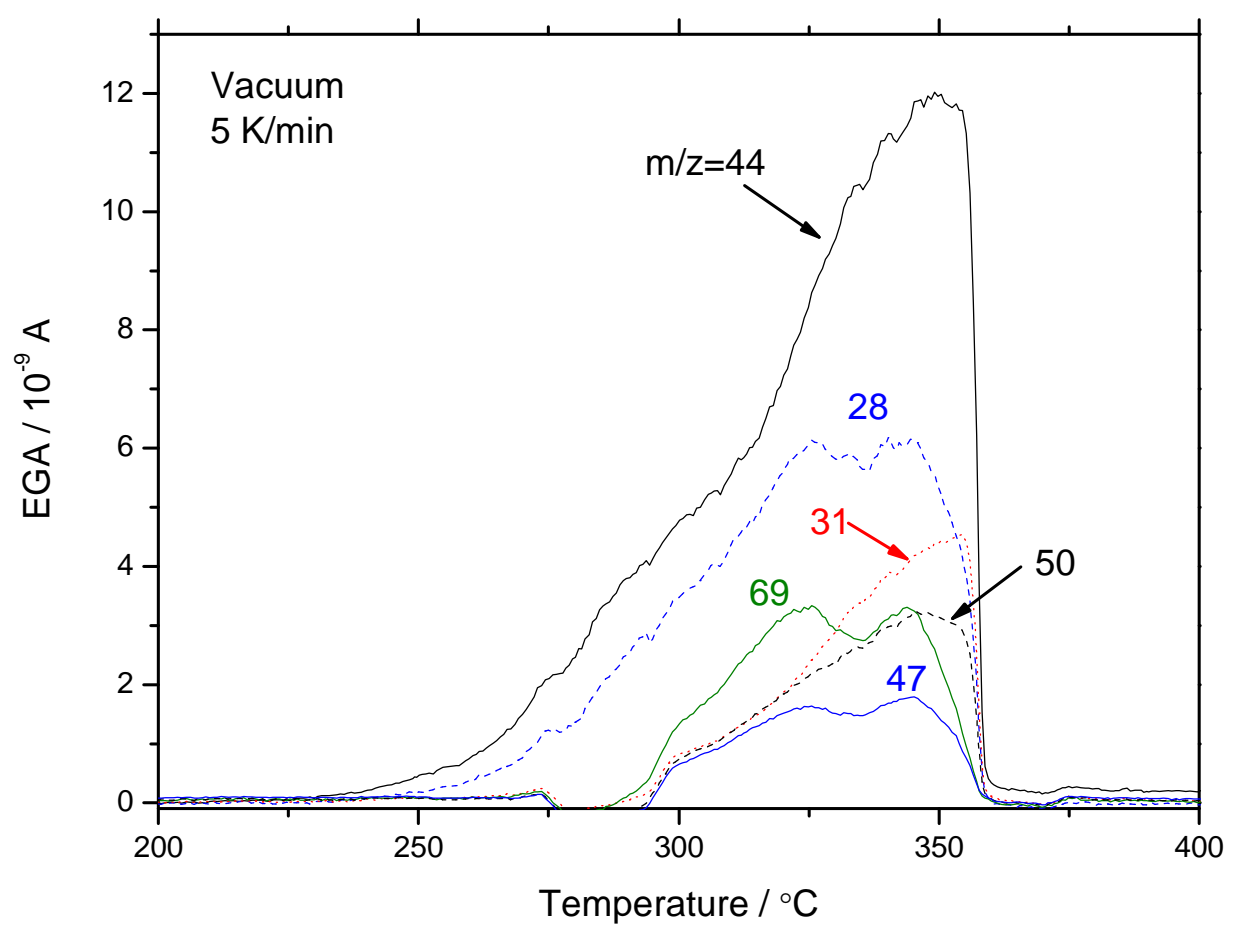

1

3 Figure. 5. EGA analysis of thermal decomposition of $\mathrm{Ba}(\mathrm{TFA})_{2}$ in vacuum $\left(10^{-6} \mathrm{mbar}\right)$, $4 m_{S}=0.98 \mathrm{mg} / \mathrm{cm}^{2}$. Heating rate is $5 \mathrm{~K} / \mathrm{min}$. Only the more intense ions have been 5 plotted.

6 


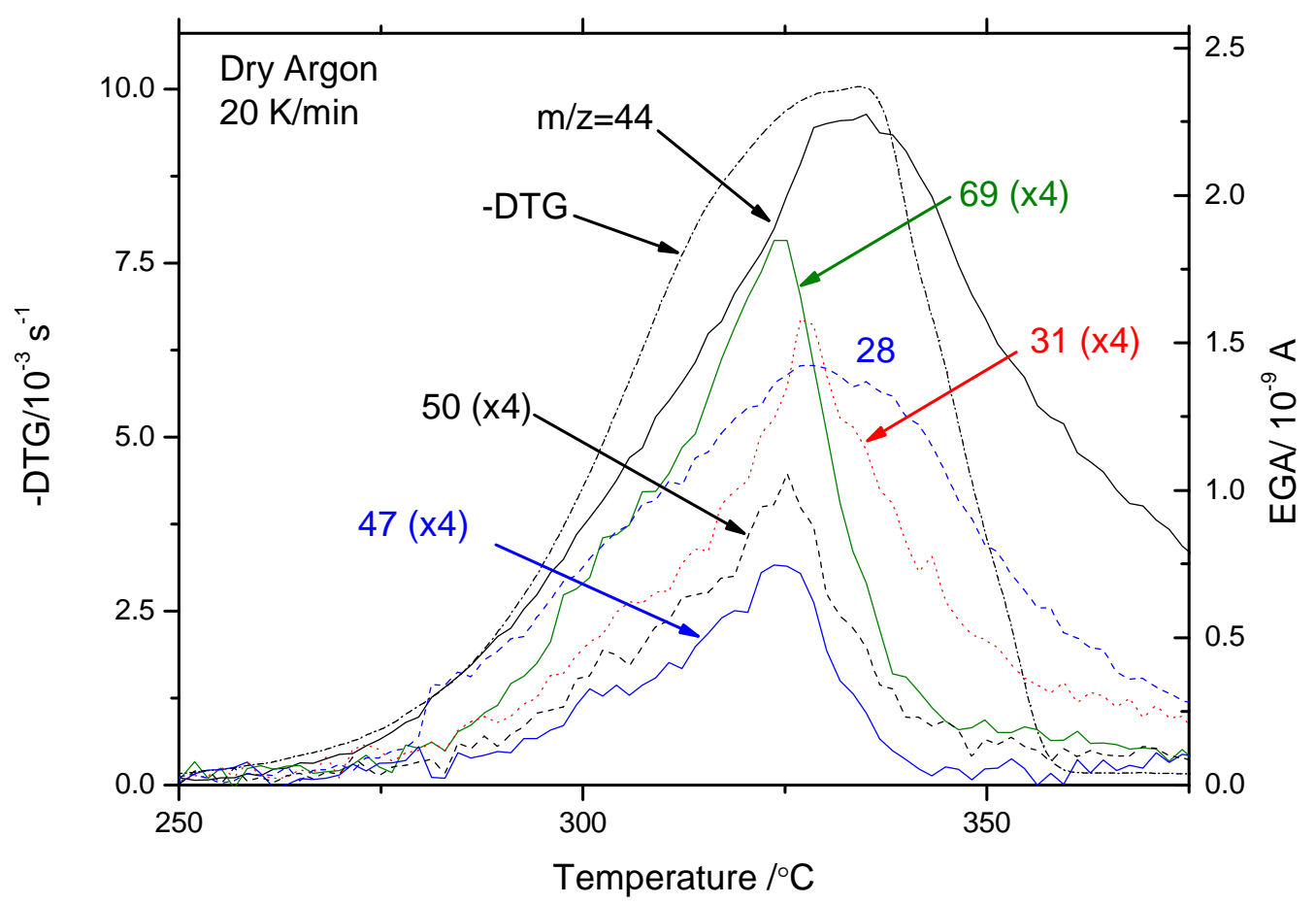

1

3 Figure 6. Simultaneous TG-EGA analysis of thermal decomposition of $\mathrm{Ba}(\mathrm{TFA})_{2}$ in 4 dry argon for a very thick film $\left(m_{S}=5.24 \mathrm{mg} / \mathrm{cm}^{2}\right)$. EGA curves correspond to the more 5 intense ions. Heating rate is $20 \mathrm{~K} / \mathrm{min}$. To facilitate the comparison, some curves have 6 been rescaled by a factor $4(\mathrm{x} 4)$. 


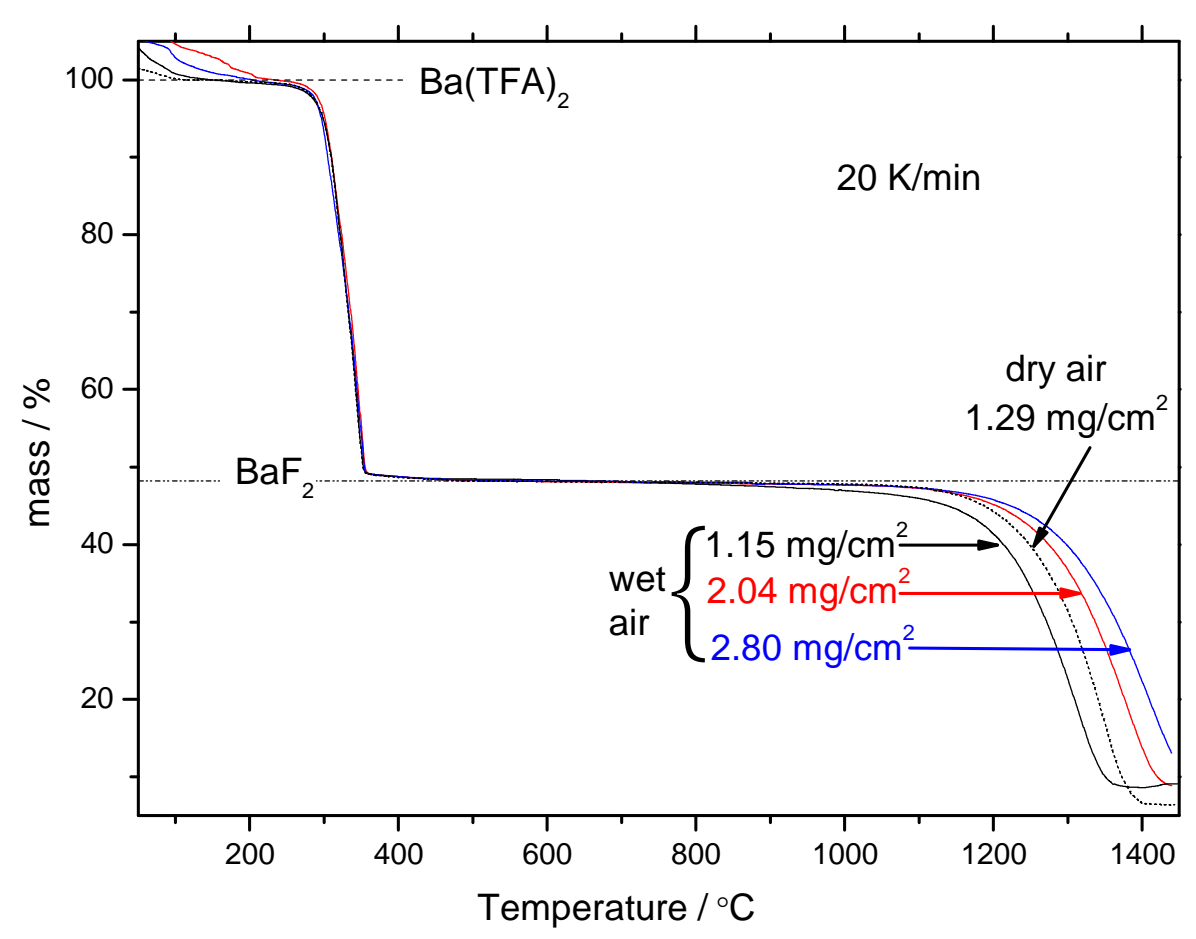

1

3 Figure 7. TG curves for thermal decomposition of $\mathrm{Ba}(\mathrm{TFA})_{2}$ heated at $20 \mathrm{~K} / \mathrm{min}$ in wet 4 (solid lines) and dry (dashed lines) synthetic air $\left(\mathrm{p}\left(\mathrm{O}_{2}\right)=21 \%\right)$. The mass has been 5 normalized to the mass after dehydration. Horizontal dotted line is the expected final 6 mass for the formation of $\mathrm{BaF}_{2}$. Precursor mass per unit surface of a single film is 7 indicated.

8 